\title{
Basic Study on the Application of Novel Functional Monomers to a Denture Base Resin
}

\author{
Shigeaki KURATA, Kumiko MORISHITA, Kazuo SHIMOYAMA and Kozo UMEMOTO \\ Department of Biomaterials and Devices, Kanagawa Dental College, 82 Inaoka-cho, Yokosuka, Kanagawa 238-8580, Japan \\ Corresponding author, Shigeaki KURATA; E-mail: kuratas@kdcnet.ac.jp
}

Received September 10, 2007/Accepted November 2, 2007

\begin{abstract}
To improve the mechanical properties and to reduce the water sorption amount of denture base resins, the polymerization characteristics of three novel fluoro-substituted monomers (MAF-TBN, MAF-MAE, MAF-TBN) and three styrene-type monomers (PTBS, PEES, PACS) were studied, as well as the copolymerization of these monomers with MMA. Subsequently, the mechanical properties and water sorption of the copolymers prepared from these monomers and MMA were evaluated. The polymerization reactivity of the monomers by BPO was lower than MMA, except for PACS. However, the copolymerization reactivity of the monomers with MMA was good, except for MAF-TBN. The copolymer of MAF-MAE and MMA in three fluoro-substituted monomers and PACS and MMA in three styrene-type monomers showed similar mechanical properties and extremely low water sorption compared with those of PMMA.
\end{abstract}

Keywords: Functional monomer, Polymerization, Mechanical Property

\section{INTRODUCTION}

Poly(methyl methacrylate) (PMMA) is widely used in denture base resins. However, PMMA has posed several problems in clinical applications, such as poor water resistance, decrease in mechanical strength by water absorption, polymerization shrinkage, and monomer volatility. Against this background, novel resins with good mechanical properties and lower water sorption in the place of PMMA are required.

To circumvent the abovementioned drawbacks, we have studied some monomers to date. For example, to improve the water resistance of PMMA, hydrophobic alkyl methacrylate and bis(methacryloyloxy) dimethylsiloxane oligomer were synthesized, and the mechanical properties of the copolymers of these monomers and MMA were evaluated ${ }^{1,2}$. The mechanical properties and water resistance of the copolymers were improved in comparison with PMMA, and the polymerization shrinkage was decreased. Increase in the monomer content for the copolymers was able to renders resin with the required hardness, but there was also increase in brittleness ${ }^{11}$. Decrease in the monomer content, on the other hand, did not improve water resistance and mechanical properties. In the case of the siloxane oligomer, the water resistance of the copolymer was improved, but the mechanical properties were poor compared with those of PMMA ${ }^{2}$.

To improve the mechanical properties and to decrease the water sorption of resins, it has been proposed to introduce fluorine groups to the resins. Octafluoropentyl and 2,2,2-trifluoroethyl methacrylate have been investigated as resin binders of direct filling resins ${ }^{3)}$ and denture base resins ${ }^{4)}$ respectively. As for fluoroalkyl methacrylates, they were applied as visible light-cured soft resins ${ }^{5)}$ or as a modifier to the surface of denture base resins ${ }^{6)}$ to inhibit bacte- rial adherence. However, the mechanical properties of the resins were not improved. The poor strength might be due to decrease in interaction, such as van der Waals' force and the orientation of polar groups, among the polymer molecules by the substitution of the methyl group by long fluoroalkyl group at the ester position. Unfortunately, trifluoromethyl methacrylate has not been successfully prepared because it is unstable at ambient temperature. On the other hand, the polymer prepared from methyl $\boldsymbol{\alpha}$-fluoroacrylates showed better mechanical properties, but poor water resistance ${ }^{7}$.

The purpose of this study was to investigate the polymerization characteristics of three novel fluoro-substituted monomers and three styrene-type monomers, as well as the copolymerization of these monomers and MMA. Thereafter, the mechanical properties and water sorption of the copolymers prepared from these monomers and MMA were evaluated.

\section{MATERIALS AND METHODS}

\section{Preparation of polymers and copolymers}

Figure 1 shows the new functional monomers examined in this study. These monomers were supplied by Tosoh Corp. (Yamaguchi, Japan). A quantity of $10 \mathrm{~g}$ of each monomer and $50 \mathrm{mg}$ of benzoyl peroxide (BPO; Wako Pure Chemical Industries, Osaka, Japan) as an initiator were placed into two types of glass tubes. There were nine glass tubes of $4 \mathrm{~mm}$ inner diameter and $100 \mathrm{~mm}$ length, and one glass tube of $10 \mathrm{~mm}$ inner diameter and $100 \mathrm{~mm}$ length. The tubes were then sealed without nitrogen substitution and with the air removed. Sealed monomers were polymerized at $51^{\circ} \mathrm{C}$ for 24 hours in a water bath followed by $100^{\circ} \mathrm{C}$ for one hour in an oven. The mixture of each monomer and methyl methacrylate 
<smiles>C=C(C(=O)OC(C)(C)C)C(F)(F)F</smiles><smiles>C=C(C(=O)OC1(C)C2CC3CC(C2)CC1C3)C(F)(F)F</smiles><smiles>CC(C)(C)OC(=O)C1(C(F)(F)F)CC2C=CC1C2</smiles><smiles>C=Cc1ccc(OC(C)(C)C)cc1</smiles><smiles>C=Cc1ccc(OC(C)=O)cc1</smiles><smiles>C=Cc1ccc(OC(C)OCC)cc1</smiles>

MAF-TBE

$\alpha$-Trifluoromethacrylic acid t-butyl

Colorless liquid, b.p. $37{ }^{\circ} \mathrm{C} / 3.1 \mathrm{kPa}$

MAF-MAE

$\alpha$-Trifluoromethacrylic acid 2-methyl-

2-adamantyl

Colorless liquid, b.p. $95{ }^{\circ} \mathrm{C} / 0.05 \mathrm{kPa}$

MAF-TBN

2-Trifluoromethylnorbornene-

2-carboxylic acid t-butyl

Colorless liquid, b.p. $56{ }^{\circ} \mathrm{C} / 0.13 \mathrm{kPa}$

PTBS

p-t-Butoxystyrene

Pale yellow liquid, b.p. $92{ }^{\circ} \mathrm{C} / 0.67 \mathrm{kPa}$

PACS

p-Acetoxystyrene

Pale yellow liquid, b.p. $260{ }^{\circ} \mathrm{C} / 101.3 \mathrm{kPa}$

PEES

p-(1-Ethoxyethoxy)styrene

Pale yellow liquid, b.p. $87{ }^{\circ} \mathrm{C} / 0.13 \mathrm{kPa}$

Fig. 1 Functional monomers used in this study.

(MMA) (Wako Pure Chemical Industries), containing $50 \mathrm{ppm}$ of hydroquinone, was polymerized by the procedure described above. The molar ratio of each monomer in the mixture was 10,20 , and $30 \%$. Various specimens were fabricated from the polymerized bulks by use of a diamond cutting machine (Isomet, Buehler Ltd., USA), and the fabricated surfaces were polished with \#1000 waterproof paper under running water.

\section{Bending test}

A universal testing machine (AGS-1000, Shimadzu Co., Kyoto, Japan) was used to carry out the bending test at a crosshead speed of $1 \mathrm{~mm} / \mathrm{min}$ and a chart speed of $100 \mathrm{~mm} / \mathrm{min}$. Five test pieces with dimensions of $4 \mathrm{~mm}$ diameter and $25 \mathrm{~mm}$ length for the bending test and $4 \mathrm{~mm}$ diameter and $8 \mathrm{~mm}$ length for the compressive test were used. The test pieces were stored in $37^{\circ} \mathrm{C}$ water for $50 \pm 2$ hours prior to the tests. To determine the bending strength, a specimen was placed in a three-point bending fixture with a span of $20 \mathrm{~mm}$. Bending modulus was calculated from the linear portion of the load-time curve up to the proportional limit obtained by the bending test.

\section{Water sorption test}

Three specimens with dimensions of $10 \mathrm{~mm}$ diameter and $1 \mathrm{~mm}$ thickness were used. After polishing the cut surfaces of the specimens with \#1000 waterproof papers under running water, the specimens were cleaned by ultrasonic washer in ion exchange water for two minutes twice. The test was carried out according to ISO $1567^{8)}$, whereby the specimens were stored in a desiccator at $37^{\circ} \mathrm{C}$ until the weight of the specimens became constant (A mg). Next, these specimens were immersed in water at $37^{\circ} \mathrm{C}$ for seven days prior to measurement (B $\mathrm{mg})$. Water sorption $\left(\mathrm{C} \mathrm{mg} / \mathrm{cm}^{2}\right)$ was then calculated using the following equation:

$\mathrm{C} \mathrm{mg} / \mathrm{cm}^{2}=[\mathrm{B}-\mathrm{A}](\mathrm{mg}) /$ surface area of specimen $\left(\mathrm{cm}^{2}\right)$

\section{Statistical analysis}

All data collected in this study were analyzed statistically using Student's t-test $(\mathrm{p}<0.05)$.

\section{RESULTS}

\section{Polymerization characteristics of the monomers}

Table 1 shows the polymerization reactivity results of the monomers by BPO. All monomers showed lower polymerization reactivity even at a high temperature at $100^{\circ} \mathrm{C}$, except for PACS. In particular, MAF-TBE and MAF-TBN did not polymerize at all. The products obtained from MAF-MAE and PEES were a very viscous liquid, while that of PTBS was a soft solid. In contrast, PACS showed higher reactivity than the other monomers, and the polymer obtained was hard but brittle. 
Table 1 Polymerization characteristics of the monomers by $\mathrm{BPO}$

\begin{tabular}{lccl}
\hline Monomer & at $60^{\circ} \mathrm{C}$ & at $100^{\circ} \mathrm{C}$ & \multicolumn{1}{c}{ Form $^{* 2}$} \\
\hline MAF-TBE & - & - & \\
MAF-MAE & - & + & Viscous \\
MAF-TBN & - & - & \\
PTBS & $-{ }^{* 1}$ & $+* 1$ & Soft \\
PACS & + & + & Hard \& Brittle \\
PEES & - & + & Viscous \\
\hline
\end{tabular}

*1: (+)Polymerization, (-)Non-ploymerization

$* 2$ : Form of the cured resin

Table 2 Copolymerization characteristics of MMA-monomer mixtures by $\mathrm{BPO}$

\begin{tabular}{lc}
\hline Monomer & at $60^{\circ} \mathrm{C}$ \\
\hline MAF-TBE & $+{ }^{* 1}$ \\
MAF-MAE & + \\
MAF-TBN & - \\
PTBS & + \\
PACS & + \\
PEES & + \\
\hline
\end{tabular}

*1: (+)Polymerization, (-)Non-ploymerization

Table 3 Compressive strengths of the copolymers (MPa)

\begin{tabular}{lccc}
\hline & \multicolumn{3}{c}{ Content } \\
\cline { 2 - 4 } Monomer & $10 \mathrm{~mol} \%$ & $20 \mathrm{~mol} \%$ & $30 \mathrm{~mol} \%$ \\
\hline MAF-TBE & $114(5)^{*}$ & $90(2)$ & $61(4)$ \\
MAF-MAE & $118(5)$ & $115(5)^{*}$ & $109(4)^{*}$ \\
MAF-TBN & $72(1)$ & $19(1)$ & Rubber-like \\
PTBS & $111(2)^{*}$ & $98(3)$ & $69(3)$ \\
PACS & $116(3)^{*}$ & $110(3)^{*}$ & $110(3)^{*}$ \\
PEES & $96(2)$ & $83(3)$ & $67(3)$ \\
\hline
\end{tabular}

*NO significantly difference form PMMA: 112 (5) (p>0.05)

Copolymerization characteristics of the monomer and $M M A$

Table 2 shows the copolymerization results of the monomers and MMA by BPO. The mixture of MMA and MAF-TBN was not polymerized at $60^{\circ} \mathrm{C}$ by BPO, while other monomer mixtures were smoothly polymerized. In light of these results, the mechanical properties and water sorption of the copolymers prepared from the monomers and MMA were examined.
Table 4 Bending strengths of the copolymers (MPa)

\begin{tabular}{lccr}
\hline & \multicolumn{3}{c}{ Content } \\
\cline { 2 - 4 } Monomer & $10 \mathrm{~mol} \%$ & $20 \mathrm{~mol} \%$ & $30 \mathrm{~mol} \%$ \\
\hline MAF-TBE & $167(13)^{*}$ & $127(8)$ & $81(2)$ \\
MAF-MAE & $152(14)^{*}$ & $104(14)$ & $69(18)$ \\
MAF-TBN & $97(1)$ & $25(1)$ & Rubber-like \\
PTBS & $153(3)^{*}$ & $124(2)$ & $90(6)$ \\
PACS & $156(13)^{*}$ & $167(7) *$ & $123(15)$ \\
PEES & $145(2)$ & $132(8)$ & $97(8)$ \\
\hline * NO significantly difference form PMMA: $160(14)(\mathrm{p}>0.05)$
\end{tabular}

Table 5 Bending moduli of the copolymers (GPa)

\begin{tabular}{cccc}
\hline & \multicolumn{3}{c}{ Content } \\
\cline { 2 - 4 } Monomer & $10 \mathrm{~mol} \%$ & $20 \mathrm{~mol} \%$ & $30 \mathrm{~mol} \%$ \\
\hline MAF-TBE & $2.71(0.13)$ & $2.24(0.10)^{*}$ & $1.56(0.08)$ \\
MAF-MAE & $2.84(0.03)$ & $2.78(0.08)$ & $2.63(0.13)$ \\
MAF-TBN & $1.77(0.02)$ & $0.50(0.06)$ & Rubber-like \\
PTBS & $2.39(0.13)^{*}$ & $2.22(0.02)$ & $1.81(0.01)$ \\
PACS & $2.47(0.04)$ & $2.39(0.03)$ & $1.93(0.07)$ \\
PEES & $2.47(0.04)$ & $2.07(0.03)$ & $0.90(0.01)$ \\
\hline * NO significantly difference form PMMA. $2.29(0.05)(\mathrm{p}>0.05)$
\end{tabular}

Table 6 Water sorption values of the copolymers $\left(\mu \mathrm{g} / \mathrm{cm}^{2}\right)$

\begin{tabular}{lrcc}
\hline & \multicolumn{3}{c}{ Content } \\
\cline { 2 - 4 } Monomer & $10 \mathrm{~mol} \%$ & $20 \mathrm{~mol} \%$ & $30 \mathrm{~mol} \%$ \\
\hline MAF-TBE & $0.73(0.04)$ & $0.46(0.01)$ & $0.06(0.00)$ \\
MAF-MAE & $0.63(0.03)$ & $0.39(0.06)$ & $0.25(0.04)$ \\
MAF-TBN & $0.51(0.03)$ & $0.00(0.01)$ & Rubber-like \\
PTBS & $0.82(0.00)$ & $0.66(0.06)$ & $0.49(0.03)$ \\
PACS & $1.00(0.00)$ & $1.02(0.03)$ & $0.86(0.03)$ \\
PEES & $0.95(0.09)$ & $0.64(0.00)$ & $0.41(0.00)$ \\
\hline
\end{tabular}

* NO significantly difference form PMMA: $1.16(0.13)(\mathrm{p}>0.05)$

Mechanical properties and water sorption values of the copolymers

Compressive and bending strengths, bending moduli and water sorption values of the copolymers are shown in Tables 3, 4, 5, and 6 respectively. Compressive strength of the copolymer containing $10 \mathrm{~mol} \%$ of MAF-MAE was higher than that of PMMA $(p<0.05)$. For compressive strengths that were comparable with that of PMMA, they were rendered by copoly- 


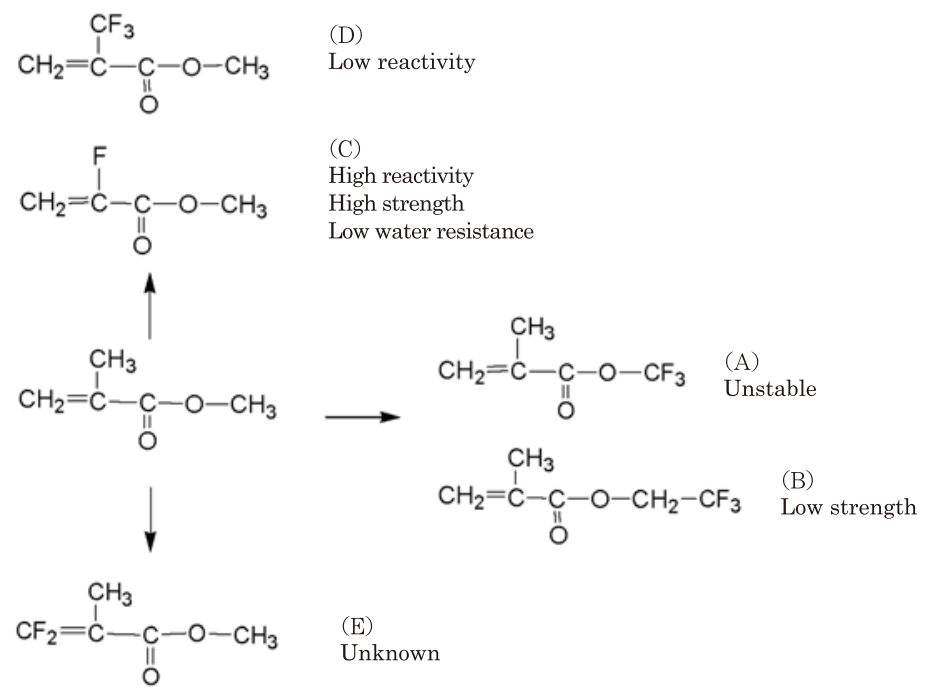

Fig. 2 Reactivity and characterization of fluoro-substituted monomers.

mers containing $10 \mathrm{~mol} \%$ of MAF-TBE, PTBS and PACS, as well as those containing 20 and $30 \mathrm{~mol} \%$ of MAF-MAE and PACS. All copolymers containing MAF-TBN and PEES yielded compressive strengths lower than that of PMMA.

For bending strengths that were comparable with that of PMMA, they were rendered by copolymers containing $10 \mathrm{~mol} \%$ of MAF-TBE, MAF-MAE, PTBS, and PACS. Copolymers containing MAF-TBN and PEES yielded lower bending strengths. The bending strengths of all copolymers decreased with increase in monomer content, except for PACS.

For copolymers containing $10 \mathrm{~mol} \%$ of MAFTBE, MAF-MAE, PACS, and PEES, their bending moduli were higher than that of PMMA. In particular for MAF-MAE, its bending modulus was higher than that of PMMA within the concentration range studied. For copolymers containing 20 and $30 \mathrm{~mol} \%$ of the monomers, except for MAF-MAE and PACS, their bending moduli were lower than that of PMMA.

For all the copolymers examined in this study, their water sorption values were lower than that of PMMA. In particular for MAF-MAE and MAF-TBN, their values decreased to about half of that of PMMA. With increase in monomer content, the water sorption values of all copolymers steeply decreased, except for PACS.

\section{DISCUSSION}

To improve the mechanical properties and to decrease the water sorption of denture base resins, crosslinking agents have been added to $\mathrm{MMA}^{1)}$. As a result, the resins became hard but brittle. Denture base resins must not only have hardness, but also toughness. The water sorption behavior of resins can be decreased by introducing hydrophobic groups. On this note, we attempted to apply three types of novel monomers with bulky hydrophobic group as denture base resin monomers. The first type pertained to three styrene compounds with butoxy, acetoxy, or 1-ethoxyethoxy group. The second type comprised two $\boldsymbol{\alpha}$-trifluoromethacrylic acids with tert-butyl or 2-methyl-2-adamantyl group. The third type was a 2-trifluoromethyl norbornene-2-carboxylic acid with a tert-butyl group.

Polymerization reactivity of the monomers examined in this study was poor, except for PACS. It was suggested that the growth reaction in radical polymerization was inhibited by the steric hindrance of the bulky groups. Therefore, the addition of MMA without bulky groups facilitated the copolymerization reaction of the monomers and MMA, except for MAF-TBN. It is noteworthy that MAF-TBN showed excessively poor reactivity. This could be due to the double bond being constricted by its bulky bicyclo ring or that the electron density of the double bond was uniform between two carbons.

On the decrease in compressive and bending strengths and bending modulus, it might be due to the long groups in the side chain of the copolymers after polymerization. On water sorption, the corresponding values of the copolymers drastically decreased with increase in hydrophobic monomer content, except for PACS. In the case of PACS-MMA copolymer, its water sorption value was slightly lower than that of PMMA. This slight difference could be attributed to the hydrophilic carboxyl groups in the side chain of the polymer. As a result, the copolymer of MAF-MAE and MMA in three fluoro-substituted monomers and that of PACS and MMA in three styrene type monomers showed similar mechanical prop- 
erties and extremely low water sorption values compared with those of PMMA. In light of these results, we concluded that it might be difficult to improve the mechanical properties of PMMA by substituting bulky and hydrophobic groups for MMA.

We have studied the polymerization reactivity of several fluorine-substituted methacrylic acid derivatives and the mechanical properties of the resins obtained following the polymerization thereof ${ }^{7}$. In the present study, the polymerization reactivity of $\boldsymbol{\alpha}$ trifluoromethacrylic acid derivatives, that had a trifluoromethyl group at $\boldsymbol{\alpha}$-position of acrylic acid, was markedly low compared with that of MMA. Figure 2 summarizes the results obtained in this study and reported in previously published papers ${ }^{7,9)}$. Trifluoromethyl methacrylate (A in Fig. 2) was unstable, and the homopolymer prepared from 2,2,2-trifluoroethyl methacrylate (B) had low strength. The polymerization reactivity of methyl $\boldsymbol{\alpha}$-fluoroacrylate (C) was very good, and the polymer obtained showed better mechanical properties compared with that of PMMA, but poor water resistance ${ }^{7}$. Methyl $\boldsymbol{\alpha}$-chloroacrylate, in which fluorine was substituted with chlorine, was an interesting monomer as a dental base monomer ${ }^{10)}$. Its monomer reactivity was higher than that of methyl $\boldsymbol{\alpha}$-fluoroacrylate (MFA), and $\mathrm{Tg}\left(c a .145^{\circ} \mathrm{C}\right)$ of the homopolymer was also higher than those of PMMA and poly(MFA), ca. 124 and $134^{\circ} \mathrm{C}$ respectively $^{7}$. As for methyl $\boldsymbol{\alpha}$-(trifluoromethyl)acrylate (D), it had very low reactivity in polymerization ${ }^{9}$. On the reactivity of methyl $\beta$-(difluoro)methacrylate (E) and the mechanical properties of the polymer thereof, they were still unknown.

\section{ACKNOWLEDGEMENTS}

The authors thank Tosoh Corporation for supplying the fluoro-substituted monomers and styrene-type monomers used in this study.

\section{REFERENCES}

1) Umemoto K, Kurata S. Study on a new crosslinking agent with low water sorption for poly (methyl methacrylate) resin denture. Bull Kanagawa Dent Col 1993; 21: 11-15.

2) Umemoto K, Kurata S. Basic study of a new denture base resin applying hydrophobic methacrylate monomer. Dent Mater J 1997; 16: 21-30.

3) Craig RG, Douglas WH. Properties of a new biomaterials composite of bis-phenol A bis-ethylene glycol dimethacrylate, octafluoropentyl methacrylate, and silanated quartz. IUPAC Macro 1982, Amherst, July 12-16.

4) Kuo Y, Yokoyama Y, Kojima K, Kojima M, Kadoma Y, Masuhara E. Studies on dental acrylic resins containing 2,2,2-trifluoroethyl methacrylate. J Jpn Soc Dent Appar Mater 1983; 2: 50-57.

5) Hirano $\mathrm{H}$, Ohe $\mathrm{Y}$, Kadoma Y, Imai Y. Study on denture liner consisting of fluoropolymer and MMA. J J Dent Mater 1992; 11: 947-954.

6) Kubota T, Kobayashi M, Hayashi R, Ono A, Mega J. Influence of carbon chain length of fluorinated alkyl acrylate on mechanical properties of denture base resin. Int Oral Med Sci 2005; 4: 92-96.

7) Kurata S, Yamazaki N. Mechanical properties of poly(alkyl $\boldsymbol{\alpha}$-fluoroacrylate)s as denture-base materials. J Dent Res 1989; 68: 481-483.

8) International Standards Organization. ISO 1567: 1988, Dentistry - Denture base polymers, pp.1-9.

9) Ito H, Dolores CM, Willson CG. Polymerization of methyl $\quad \alpha$-(trifluoromethyl)acrylate and $\alpha$ (trifluoromethyl)acrylonitrile and copolymerization of these monomers with methyl methacrylate. Macromolecules 1982; 15: 915-920.

10) Yamada B, Kotani T, Yoshioka M, Otsu T. Determination of absolute rate constants for free radical polymerization of ethyl $\boldsymbol{\alpha}$-fluoroacrylate and characterization of the polymer. J Poly Sci, Poly Chem Edition 1984; 22: 2381-2393. 